\title{
POLITTICAS SOCIAIS DE ATENDIMENTO ÀS CRIANÇAS E AOS ADOLESCENTES NO BRASIL
}

\author{
JOSÉ ROBERTO RUS PEREZ \\ Professor da Faculdade de Educação e coordenador do Núcleo de Estudos de \\ Políticas Públicas da Universidade Estadual de Campinas \\ rusperez@nepp.unicamp.br
}

\section{ERIC FERDINANDO PASSONE}

Doutorando da Faculdade de Educação e pesquisador associado do Núcleo de Estudos de Políticas Públicas da Universidade Estadual de Campinas

eric@nepp.unicamp.br

\begin{abstract}
RESUMO
Este artigo analisa a emergência e o desenvolvimento das políticas sociais de atendimento infanto-juvenil concomitante ao processo de desenvolvimento do sistema de proteção social nacional, focalizando algumas das principais representações atribuídas à infância, de acordo com o período histórico e político de cada época. Busca-se apresentar a noção de infância instituída sob a constituição do aparato do Estado de Bem-Estar brasileiro, de forma a situá-la em um contexto mais amplo de transformações históricas e políticas que envolveram a emergência e consolidação das políticas sociais destinadas ao atendimento à criança e ao adolescente no Brasil ao longo do século $X X$ e início do século XXI.

POLITICAS SOCIAIS - CRIANÇAS - ADOLESCENTES - CIDADANIA
\end{abstract}

\begin{abstract}
SOCIAL POLICIES FOR CHILDREN AND ADOLESCENTS IN BRAZIL. This article analyses the emergence and development of social policies for children and adolescents attendance that are in line with the development process of the Brazilian social protection system, focusing on some of the main representations attributed to childhood, according to the historical and political periods. It seeks to present the notion of childhood instituted under the constitution of the Brazilian welfare state, in such a way as to place it within the broader context of the historical and political transformations that involved the emergence and consolidation of the social policies directed towards children and adolescents in Brazil in the 20 century and the beginning of the $21^{\text {st }}$. SOCIAL POLITICS - CHILDREN - ADOLESCENTS - CITIZENSHIPS
\end{abstract}


Entre os estudos realizados no campo das políticas sociais no Brasil, há um conjunto de trabalhos que propala a inexistência de um efetivo sistema de proteção social até 1990, devido à insuficiência do atendimento diante do abismo sociocultural e econômico existente na sociedade ou mesmo do frágil reconhecimento dos direitos civis, políticos e sociais na nossa cultura política e no incipiente estado democrático que possuímos. Tais estudos consideram o "arcabouço social" existente apenas como um instrumento de controle e legitimação da ordem política e social, principalmente em períodos autoritários e populistas.

Encontram-se também estudiosos que demonstram que no período de 1930 a 1980 ocorreu a introdução, expansão e consolidação jurídicoinstitucional dos mecanismos de garantia e proteção sociais, como a previdência social e a assistência; a construção de uma rede de ensino básico e científico; a política de atenção à saúde e a política habitacional etc., enfim, a institucionalização de um conjunto básico e essencial de políticas, diretrizes, programas, normas e regras que representaram um avanço, mesmo que às avessas e insuficientemente, dos direitos sociais no país (Draibe, 1995; Faleiros, 1995; Núcleo de Estudos de Políticas Públicas - Nepp, 1991).

notório é que, no século $X X$, os três momentos mais significativos de transformação institucional e de produção legal estiveram associados às três profundas alterações estruturais que envolveram o Estado brasileiro, a saber: o Estado Novo, caracterizado pelo autoritarismo populista de Getúlio Vargas (1930 a 1945); a ditadura militar e o retrocesso dos precários direitos políticos e civis, (1964 a 1985), e o período de redemocratização, a partir de 1985 (Carvalho, 2004; Nepp, 199|), culminando na Constituição de 1988 e no reconhecimento dos direitos constitutivos de cidadania para todos os brasileiros.

Paralelamente, constitui-se no país uma noção particular de infância e adolescência que protela políticas sociais de atendimento à criança e ao adolescente como direitos de cidadania até a década de 1980. A proclamação da Constituição Cidadã (Brasil, 1988) e da aprovação do Estatuto da Criança e do Adolescente - ECA (Brasil, 1990a), um conjunto de direitos civis, sociais, econômicos e culturais de promoção e proteção - alteraram esse paradigma. Atualmente, o ECA demanda do Estado brasileiro e da sociedade política e civil esforços e continuidade nas ações visando, por um lado, à formulação, implementação, monitoramento e controle social de políticas constitucionais e estatutárias e por outro, ações mobilizadoras e societais capazes de ressignificar 
a concepção arcaica de infância e juventude presente no imaginário social da população. Essa concepção, conforme o previsto no Estatuto, entende que a criança e o adolescente devam estar assegurados por políticas públicas de proteção, promoção e direitos, bem como as suas respectivas famílias (Rizzini, Naiff, Baptista, 2006).

A instituição da noção de direitos da infância e da adolescência, inicialmente inexistente e relegada ao trato do mundo do privilégio privado e religioso, posteriormente, incorporada por um Estado autoritário e monopolizador, que excluía qualquer forma de interlocução com a incipiente sociedade de então tem, paradoxalmente, representado há mais de dezoito anos uma pauta política e social que vem balizando o aprofundamento democrático das relações Estado-sociedade em torno da questão.

Considerando relevante a relação passado-presente para a compreensão do atual momento dessas políticas, este artigo procura resgatar a noção de infância instituída sob a constituição do aparato do Estado de bem-estar social brasileiro, de forma a situá-la em um contexto mais amplo de transformações históricas. A emergência e consolidação das políticas sociais destinadas ao atendimento à criança e ao adolescente foram sistematizadas em dois grandes períodos, a saber, antes e depois do surgimento do Estatuto da Criança e do Adolescente. $\bigcirc$ principal critério de delimitação entre esses dois períodos está alicerçado na concepção de infância e adolescência e nas diretrizes implícitas em decorrência dela nos arcabouços jurídicos dos respectivos períodos. Por um lado, refizemos um percurso histórico que retrata a institucionalização da infância como objeto de controle por parte do Estado brasileiro, período que registra as políticas e concepções que datam do início da república até o fim da ditadura militar; e, por outro assinalamos o período de abertura democrática do país, culminando em 1990, com a promulgação do ECA. Nele a infância e adolescência adquiriram status de sujeitos de direitos - revelando a profunda alteração representada em termos legislativos, normativos, culturais e conceituais para as diretrizes, políticas públicas e serviços destinados ao atendimento da criança e adolescência no Brasil. Será estabelecida uma cronologia consoante com as principais alterações institucionais ocorridas de 1889 a 2006.

Essa contextualização histórica do atendimento infanto-juvenil visa demarcar os períodos políticos em que foram desenvolvidos os serviços de atendimento e estabelecidas as principais normatizações e legislações, referidas de acordo com a periodicidade estipulada, bem como as características e diretrizes 
da política social de atendimento à criança e ao adolescente, oferecendo um panorama do início, do desenvolvimento e da consolidação do sistema de proteção social brasileiro ao longo do século $X X$ e início do Século $X X \mid$.

\section{INSTITUCIONALIZAÇÃO DA INFÂNCIA COMO OBJETO DE CONTROLE DO ESTADO (I889-1985)}

Nesta primeira parte do artigo, são indicados os períodos relacionados ao tratamento oferecido aos jovens no Brasil, abrangendo: a República Velha (I 889 a 1930); o autoritarismo populista (1930 a 1945) com a instituição do Serviço de Assistência ao Menor - SAM -, entidade de contenção-repressão infanto-juvenil; a expansão centralizada das políticas sociais sob a democracia populista ( 945 a 1964), período também caracterizado pelo fracasso do SAM e, subsequentemente, pela emergência da Fundação Nacional do Bem-Estar do Menor - Funabem -, no governo ditatorial (I 964 a 1985), ver quadro I.

QUADRO I

CONTEXTUALIZAÇÃO HISTÓRICA DO ATENDIMENTO À INFÂNCIA NO BRASIL (I889-1985)

\begin{tabular}{|c|c|c|}
\hline Períodos & Principais normatizações e legislações & Principais características \\
\hline $\begin{array}{l}\text { Primeiros passos: } \\
\text { marcos legais e } \\
\text { normatizações } \\
(\text { | 889-1930) }\end{array}$ & $\begin{array}{l}\text { - Código Criminal do Império ( } 1830 \text { ) } \\
\text { - Lei do Ventre Livre (I87|) } \\
\text { - Código Penal da República (I890) } \\
\text { - Código de Menores (1927) }\end{array}$ & $\begin{array}{l}\text { - Infância como objeto } \\
\text { de atenção e controle do } \\
\text { Estado } \\
\text { - Estratégia médica-jurídica- } \\
\text { assistencial }\end{array}$ \\
\hline $\begin{array}{l}\text { Autoritarismo } \\
\text { Populista e } \\
\text { o Serviço de } \\
\text { Assistência ao } \\
\text { Menor (I 930- | 945) }\end{array}$ & $\begin{array}{l}\text { - Departamento Nacional da Criança } \\
\text { (Decreto-Lei n. } 2.024 \text { de 1940) } \\
\text { - Serviço de Assistência ao Menor } \\
\text { (Decreto n. } 3.799 \text { de 194I) } \\
\text { - Estabelece a Legião Brasileira de } \\
\text { Assistência }\end{array}$ & $\begin{array}{l}\text { - Avanço estatal no serviço } \\
\text { social de atendimento infantil } \\
\text { - Organização da proteção } \\
\text { à maternidade e à infância }\end{array}$ \\
\hline $\begin{array}{l}\text { Democracia } \\
\text { populista } \\
(1945-1964)\end{array}$ & $\begin{array}{l}\text { - Serviço de Colocação Familiar (Lei } \\
\text { n. } 560 \text { de 1949) } \\
\text { - Serviço Nacional de Merenda Escolar } \\
\text { (Decreto n.37.106 de 1955) } \\
\text { - Instituto de Adoção (Decreto-Lei } \\
\text { n. } 4.269 \text { de 1957) } \\
\text { - Leis das Diretrizes e Bases da Educação } \\
\text { (Decreto-Lei n. 4.024 de I96I) }\end{array}$ & $\begin{array}{l}\text { - Manutenção do aparato } \\
\text { legal } \\
\text { - Regulamentação dos } \\
\text { serviços de adoção }\end{array}$ \\
\hline
\end{tabular}


(continuação)

\begin{tabular}{|c|c|c|}
\hline $\begin{array}{l}\text { Ditadura militar e a } \\
\text { Fundação Nacional } \\
\text { do Bem-Estar do } \\
\text { Menor } \\
\text { (1964-1985) }\end{array}$ & $\begin{array}{l}\text { - Fundação Nacional do Bem-Estar do } \\
\text { Menor (Decreto n. } 4.5 \text { I } 3 \text { de 1964) } \\
\text { - Diminuição da idade penal para I6 } \\
\text { anos (Lei n. } 5.258 \text { de 1967) } \\
\text { - Acordo entre o Fundo das Nações } \\
\text { Unidas para Infância e o Governo dos } \\
\text { Estados Unidos do Brasil (Decreto } \\
\text { n. } 62.125 \text { de 1968) } \\
\text { - Código de Menores (Lei n. } 6.697 \text { de } \\
\text { 1979) - "Doutrina da Situação Irregular } \\
\text { do menor" }\end{array}$ & $\begin{array}{l}\text { - Reordenamento } \\
\text { institucional repressivo } \\
\text { - Instituição do Código de } \\
\text { Menores de } 1979 \\
\text { - Contradições entre } \\
\text { a realidade vigente e } \\
\text { as recomendações das } \\
\text { convenções internacionais } \\
\text { sobre o direito da infância }\end{array}$ \\
\hline
\end{tabular}

\section{Primeiros passos: marcos legais e normatizações (I889-1930)}

Historicamente, as concepções teóricas e ações societais voltadas à infância sempre foram conflituosas. De um lado os que privilegiam ações de violência, punição e repressão. Essa parte da história no Brasil foi impiedosa e pode ser demarcada por fases características: na colonização, com a aculturação imposta às crianças indígenas pelos jesuítas; a segregação e a discriminação racial na adoção dos "enjeitados", no período imperial; o infanticídio disfarçado pela Roda dos Expostos e pela exploração do trabalho de crianças no mundo fabril, no fim do século XIX e início do XX (Pilotti, Rizzini, 1995; Rizzini, 1997, 2000). De outro, os que privilegiam a educação e a assistência, defendendo estratégias que conferem direitos de cidadania e direitos específicos à infância e adolescência (Passone, 2007).

Ao longo dos séculos XVIII e XIX, observa-se na literatura o deslocamento de poder e domínio da Igreja articulado com setores privados e públicos, para o domínio do Estado, que passaria a regulamentar e subsidiar ações da "causa da infância".

Em meados do século XIX, o período conhecido pelas Rodas dos Expostos passaria a ser alvo de críticas da Faculdade de Medicina do Rio de Janeiro, criando condições para o advento da pediatria no país, bem como as ações de entes privados, com caráter filantrópico, marcadamente influenciados pelo movimento positivista e higienista que se delineava no cenário internacional. Essas mudanças ocorriam influenciadas pela passagem do império à república e da sociedade escravocrata à organização da sociedade livre e de trabalhadores, período vinculado ao despertar do sentimento de nacionalidade e ao início da industrialização do país. 
Esse cenário proporcionou o impulso à mudança cultural em relação à infância e o início do sistema de proteção social no país. Houve no primeiro caso a incorporação da visão humanista/iluminista europeia em que processualmente se constitui um novo paradigma da infância no mundo (Nascimento, 2001 ; Pilotti, 1995; Rizzini, 1997, 2000). E, no segundo caso, um desdobramento de tendências mais gerais postas em marcha pela industrialização. Com as profundas transformações econômicas, políticas e culturais que marcaram o ocidente no século XIX, a noção de infância adquire novo sentido social, ou seja, a "criança deixa de ser objeto de interesse, preocupação e ação no âmbito privado da família e da Igreja para tornar-se uma questão de cunho social, de competência administrativa do Estado" (Rizzini, 1997, p. 24-25).

A legislação no período imperial gravitou em torno do recolhimento de crianças órfãs e abandonadas por meio de medidas assistenciais privadas e de cunho religioso e, no início da república, estabeleceram-se, gradativamente, as bases para a organização da assistência à infância. Surge, então, o primeiro Código Penal da República, em 1890, marcando o início de um debate entre os defensores da educação em detrimento do predomínio da punição.

$O$ processo de instituição da infância no Brasil do início do século $X X$ ocorreu portanto na intersecção entre medicina, justiça e assistência pública, tendo como foco a infância como objeto de atenção e controle por parte Estado.

Será da medicina (do corpo e da alma) o papel de diagnosticar na infância possibilidades de recuperação e formas de tratamento. Caberá à Justiça regulamentar a proteção (da criança e da sociedade), fazendo prevalecer a educação sobre a punição. À filantropia - substituta da antiga caridade - estava reservada a missão de prestar assistência aos pobres e desvalidos, em associação às ações públicas [...] a conexão jurídico-assistencial atuará visando um propósito comum: "salvar a criança" para transformar o Brasil. (Rizzini, 1997, p. 30)

Ressaltam, no plano das ideias, o movimento higienista associado aos médicos e filantropos, o positivismo dos militares, com imperativos de "ordem e o progresso" e a sociologia evolucionista, como determinantes da constituição e da consolidação do espaço social destinado à infância, por meio de mecanismos conhecidos como "escala da moralidade" ou da "profilaxia da criminalidade", que discriminavam as crianças desvalidas, classificadas como "menores", daquelas que possuíam infância ou eram parte da infância concebida 
como produtiva. Essa estratégia estatal prolongou-se nas décadas posteriores e marcou os primeiros passos da infância e juventude como objeto de atenção das instituições do Estado. A matriz que orientou as primeiras intervenções referentes ao público infanto-juvenil no início do Brasil republicano expressava um projeto manifesto de proteção à infância que, em última instância, visava mais à defesa da sociedade.

O Estado incorporou o debate sobre a "salvação da criança" e sobre a "regeneração social", alçando a criança a alvo das ações públicas e responsabilizando e punindo as famílias em relação aos cuidados à infância. A prevenção social e a elaboração de uma legislação específica, que permitisse a tutela do Estado e controle da sociedade, provocaram forte aliança jurídico-médicoassistencial organizada em torno do sistema de proteção ao "menor".

Em 1920 realizou-se o $1{ }^{\circ}$ Congresso Brasileiro de Proteção à Infância, impulsionando a criação de uma agenda sistematizada sobre a proteção social, e passou a ser debatida pela sociedade a regulamentação da assistência e proteção aos "menores abandonados" e "delinquentes", culminando com a promulgação do Código de Menores em 1927. Segundo Faleiros, esse código incorporou "tanto a visão higienista de proteção do meio e do indivíduo como a visão jurídica repressiva e moralista" ( 1995, p.63). Se, por um lado, previa o acompanhamento da saúde das crianças e das nutrizes por meio da inspeção médica e da higiene, por outro, intervinha no abandono físico e moral das crianças, retirando o pátrio poder dos pais; internando os abandonados socialmente e repreendendo e instituindo a liberdade vigiada aos jovens autores de infração penal. No âmbito do reconhecimento jurídico, uma das mais importantes contribuições dessa legislação foi referida no Capítulo 9 que discorre sobre a regulamentação do trabalho infanto-juvenil, proibindo que se empregassem crianças com menos de 12 anos de idade e fixando, para os jovens menores de 18 anos, jornada de trabalho de no máximo seis horas diárias.

\section{O autoritarismo populista e o serviço de assistência ao menor (1930-1945)}

A instituição do Governo Provisório da República dos Estados Unidos do Brasil, entre 1930 e 1934, e a posterior ditadura do Estado Novo, sob comando de Getúlio Vargas ( 1937 a 1945), representaram a passagem definitiva de uma sociedade de base agrária para o início de uma sociedade urbano-industrial. $\bigcirc$ caráter fortemente autoritário e nacionalista do Estado é implementado pela 
Lei de Segurança Nacional em 1935, reprimindo a ascensão de movimentos políticos, tanto da esquerda como da direita e, centralizando no governo federal praticamente todo o poder decisório e administrativo. Em virtude da atenção dispensada ao aspecto trabalhista e social à política econômico-social encetada pelo governo, principalmente nos quatro primeiros anos após a revolução de 1930, esse período se caracterizou pelo denominado autoritarismo populista, delineado pela propaganda nacionalista que, posteriormente, rendeu o título de "pai dos pobres" a Getúlio Vargas.

Os movimentos de trabalhadores tinham suas organizações limitadas e marcadas pela incipiência dos direitos políticos e civis, em flagrante paradoxo com o reconhecimento dos primeiros direitos sociais por parte do Estado. No contexto do movimento de 1930 e da instauração do golpe de 1937, sob a agenda de reformas do Estado, o Brasil organizava suas primeiras políticas sociais, nas quais eram reservadas atenções especiais à família e à infância, notadamente no campo da assistência social. Segundo Rizzini (1995, p. 136), para a Constituição de 1937, "a infância e a juventude devem ser objeto de cuidados e garantias especiais por parte do Estado"; cabe a ele assegurar-Ihes medidas "destinadas ao desenvolvimento de suas faculdades". Desse modo, o Estado proporcionaria um mínimo de condições institucionais para a preservação física e moral das crianças, e, concomitantemente, as famílias teriam o direito de "invocar o auxílio e proteção do Estado para a subsistência e educação de sua prole" (Rizzini, 1995, p. 136).

Nessa perspectiva, o autoritarismo populista passou a consolidar o serviço social oferecido pelo Estado, na medida em que incorporava o trabalhador e sua família à sociedade (Carvalho, 2004, p. I I I), caracterizando-se pela legislação sobre o trabalho e a articulação entre entes estatais e privados na provisão de serviços assistenciais. Na área infanto-juvenil, aprofundou-se a prática higienista e repressiva, que privilegiava o internamento dos menores como principal tática de contenção e atendimento à criança ou adolescente destituídos de status social. A criação do Departamento Nacional da Criança - DNCr -, do Serviço de Assistência ao Menor - SAM - e da Legião Brasileira de Assistência - LBA -, marcaram o atendimento às famílias, crianças e jovens no período.

A intenção da União de formular um sistema de assistência social à infância possibilitou a criação do Conselho Nacional de Serviço Social, ao qual caberia instituir serviços públicos de atendimento à população em condições de pobreza e miserabilidade, para atuar nas esferas de âmbito nacional, estadual 
e municipal. Em 1940, criou-se o Departamento Nacional da Criança, órgão vinculado ao Ministério da Educação e Saúde, que possuía o objetivo de "criar viva consciência social da necessidade de proteção à díade materno-infantil [...] desenvolver estudo, organizar estabelecimentos, conceber subsídio às iniciativas privadas de amparo às mães e filhos e exercer fiscalização" (Rizzini, 1995, p. 138). Em 194I foi criado o Serviço de Assistência ao Menor, órgão diretamente subordinado ao Ministério da Justiça e Negócios do Interior e ao Juizado de Menores, em razão do Decreto n. 3.799, que atribuía ao Estado poder para atuar junto aos "menores", reiteradamente qualificados como "desvalidos" e "delinquentes".

A estratégia da relação estatal/privado para o provimento de serviços e atendimento às políticas sociais foi aprofundada em 1942, com a formulação e implementação da Legião Brasileira de Assistência. Essa entidade se articularia com as demais organizações sociais do país juntamente com o Departamento Nacional da Criança, perfazendo assim o arcabouço assistencialista do populismo varguista.

Em 1943 foi aprovado o Decreto n. 6.026, que dispunha sobre as medidas aplicáveis aos menores de dezoito anos pela prática de fatos considerados infrações penais. Essa medida não alterava o anterior Código de Menores de 1927, salvo o prolongamento da inimputabilidade penal de 14 para 18 anos. Em 1944, por intermédio do Decreto n. 6.865, o SAM teve redefinidas as suas competências, cabendo-lhe orientar e fiscalizar as entidades particulares; diagnosticar os casos em que caberiam internação e ajustamento social, por meio de exames médico-psicopedagógicos; encaminhar e abrigar os menores aos estabelecimentos, bem como, supervisionar e controlar as instituições particulares que recebiam subvenções do Estado (Faleiros, 1995, p. 69).

Essa etapa marcou por um lado, o assistencialismo estatal e privado destinado às famílias trabalhadoras, permeado por um forte domínio paternalistapopulista de políticas públicas centralizadas, e, por outro, o aprofundamento de uma prática repressiva e higienista que privilegiava o internamento como principal ferramenta de proteção à criança sem infância.

Paralelamente, as bases institucionais da previdência e seguridade social eram instituídas: entre 1930 e 1943, foram criados os Institutos de Aposentadoria e Pensões e gradativamente se ampliou a legislação trabalhista. $\bigcirc$ autoritarismo e o corporativismo orgânico responsáveis pelo fortalecimento da burocracia estatal marcaram as transformações sociais em curso, tendo como base o Estado, como 
instituição e fonte de poder no processo de concessão de cidadania. As políticas securitárias são "legitimadas como políticas de massas e justificadas, segundo o ideário populista, como políticas de interesse nacional” (Nepp, |99|).

As leis trabalhistas não possuíam um caráter universal e o reconhecimento dos direitos dos trabalhadores representava, no populismo, a regulação societária por intermédio do status profissional e social do indivíduo' . O trabalhador rural estava totalmente desamparado, uma vez que a legislação contemplava somente algumas categorias regulamentadas de trabalhadores urbanos. Essa especificidade gerou - no que concerne à noção de cidadania - a representação de um povo "regulado" e "passivo" politicamente, como que incluso em uma "cidadania regulada", processo no qual a cidadania era consentida pelo Estado, não por meio de uma mediação política e civil, mas por meio de uma regulação ocupacional. No Brasil, esse dispositivo político de regulação social foi chamado de "cidadania regulada”, conceito proposto por Wanderley Guilherme dos Santos, sendo essa noção de cidadania assentada "não em um código de valores políticos, mas em um sistema de estratificação ocupacional [...]. A cidadania está embutida na profissão e os direitos do cidadão restringem-se aos direitos do lugar que ocupa no processo produtivo, tal como reconhecido por lei..." (Santos, 1989, p. 68).

Esse contexto histórico foi caracterizado, por um lado, pela ausência de uma cultura política fundada nos direitos civis e políticos que respondessem às demandas de uma progressiva incorporação da cidadania, por intermédio de políticas estatais voltadas à igualdade, bem como pela ausência de formas efetivas de participação e representação dos interesses da sociedade. Por outro, pelo fortalecimento da dinâmica distributivo-clientelista no processo de centralização da política previdenciária como mecanismo de legitimação do poder.

Desse modo, a constituição dos direitos de cidadania, no Brasil, ocorreu de forma "invertida", se comparada com o tempo histórico proposto por Marshall (1967), ou seja, a constituição dos direitos sociais foi anterior à conquista dos direitos civis e políticos, implicando a formação de um tipo especial de cidadania em que a relação entre indivíduo e Estado era caracterizada pela

I. Nessa perspectiva, o desenvolvimento e a consolidação do sistema brasileiro de proteção social foram marcados por um tipo específico de Estado de Bem-Estar cujo funcionamento se caracterizou pela meritocracia-particularista e/ou pelo modelo conservador, diferente de um modelo residual ou liberal e de um padrão institucional-redistributivista ou social-democrata (Draibe, 1995, p. 201). Esse sistema de proteção social brasileiro prevaleceu até os anos 80 do século passado. 
negociação direta entre ambos, sem passar por mecanismos de representação política e democrática. Para Carvalho (2004, p. 219 ), "a inversão da sequência dos direitos reforçou entre nós a supremacia do Estado", em detrimento dos direitos civis e políticos, em suma, de uma verdadeira noção de cidadania calcada nas liberdades individuais.

Tais aspectos implicaram a formulação de políticas sociais do período subsequente - caracterizado pela democracia populista, principalmente por reforçar a relação de clientelismo e patronagem como mecanismo central de controle político do voto da classe operária.

\section{Democracia populista (1945-1964)}

O período entre 1945 e 1964 foi reconhecido como a primeira experiência democrática da história do país, contrariando o projeto nacionalista do setor militar e de parte da elite dominante ligada a antigos setores oligárquicos. Essa fase se caracterizou pela lógica desenvolvimentista-nacionalista, marcada pelo aprofundamento da industrialização, pelo aumento do consumo interno e pela internacionalização da economia brasileira. Na área política, caracterizouse pela democracia populista, com expansão legal e institucional do sistema de proteção social, consolidando o sistema arquitetado na década de 1930. No âmbito das estruturas organizacionais do Estado, deu-se continuidade à "centralização institucional e a incorporação de novos grupos sociais aos esquemas de proteção", notadamente pelo padrão seletivo e fragmentado de intervenção social do Estado (Nepp, 1991, p. 8).

A Constituição de 1946 aprovou, entre os direitos dos trabalhadores, "o salário-mínimo familiar, a proibição do trabalho de menores de quatorze anos, a assistência sanitária e médica ao trabalhador e à gestante, a previdência social", dando continuidade à legislação sindical tuteladora da Constituição de 1937, sendo que, o direito de greve continuaria proibido. O artigo n. I 64 da Carta Magna previa a obrigatoriedade, em âmbito nacional, da assistência à maternidade, à infância e à adolescência (Faleiros, 1995, p. 7I). Em 1949 foi criado o primeiro Serviço de Colocação Familiar, por intermédio do Decreto de Lei n. 560, e, em 1957, os serviços de adoção seriam regulamentados, mediante o Instituto de Adoção, previsto no Código Civil vigente.

A questão educacional seria retomada nesse período, com o encaminhamento do anteprojeto da Lei de Diretrizes e Bases da Educação Nacio- 
nal - LDBEN -, em 1946, baseada nos princípios liberais e democráticos da constituição do mesmo ano e nas divergências sobre o estatuto público da educação e a sua obrigatoriedade ou não (Romanelli, |99|, p. |72). Entretanto, a LDB seria regulamentada somente depois de 15 anos, passando por diversas modificações até sua aprovação em 1961. O ensino privado aliou os setores da Igreja, detentores do monopólio educacional, aos estabelecimentos particulares, garantindo as relações de força que preservariam o acesso privado aos recursos da educação. No Brasil, em 1950 havia um percentual de $50 \%$ de analfabetos entre a população acima de I 5 anos e uma taxa de escolarização de apenas $26 \%$ da população de 5 a 19 anos (Romanelli, I99।). O ramo do ensino técnico prevaleceu sobre as demandas do ensino primário e da obrigatoriedade, sendo que esta última é que arregimentaria as condições mínimas para qualquer regime democrático.

Nesse ínterim, em 1953, foi criado o Ministério da Saúde que deu continuidade à assistência à infância, nos moldes do Departamento Nacional da Criança. No ano, criou-se também o Ministério da Educação e Cultura, que implementou o Serviço Nacional de Merenda Escolar, com o objetivo de fazer a suplementação alimentar da criança na escola.

O cenário de atendimento à infância passou a se caracterizar pela prática política que combinava ações assistencialistas, higienistas e repressivas, com a introdução de ações de caráter mais participativo e comunitário, orientadas pela doutrina desenvolvimentista das agências internacionais, com base em vastos setores da igreja católica. Segundo Faleiros (1995, p. 72), com o período democrático "inicia-se uma estratégia de preservação da saúde da criança e de participação da comunidade, e não somente repressiva e assistencialista”. As agências multilaterais, como o Fundo das Nações Unidas para a Infância Unicef - e a Organização das Nações Unidas para Agricultura e Alimentação FAO -, influenciariam o discurso do DNCr, cuja marca, a partir dos anos 60 do século $X X$, seria a criação de centros recreativos e a participação da comunidade nos próprios programas, como um mecanismo de desenvolvimento social e comunitário da organização social.

Com o $9^{\circ}$ Congresso Panamericano da Criança, realizado em Caracas, em 1948, aprofundou-se a discussão sobre o enfoque dado aos direitos do "menor"; e em 1959, com a Declaração Universal dos Direitos da Criança, criou-se o marco pelo qual a infância passou a ser valorizada e a criança considerada, internacionalmente, como sujeito de direitos pela Organização das Nações Unidas. 
Destacam-se entre os princípios e direitos prescritos pela declaração: o direito à igualdade, sem distinção de raça religião ou nacionalidade; o direito à especial proteção para o seu desenvolvimento físico, mental e social; o direito à alimentação, moradia e assistência médica adequadas para a criança e a mãe; o direito à educação gratuita e ao lazer infantil; o direito a ser protegido contra o abandono e a exploração no trabalho, entre outros. Instituiu-se, desta forma, como movimento social internacional, a infância como espaço social privilegiado de direitos e a criança foi considerada como pessoa em desenvolvimento, portadora de necessidades especiais e passíveis inclusive de proteção legal.

O hiato entre o marco histórico dos direitos universais da criança e a realidade do atendimento existente no Brasil levou ao questionamento do SAM e do próprio Código de Menores. A proposta de reformulação da legislação explicitou uma cisão entre os legisladores, juristas e setores do executivo ao contrapor aqueles que mantinham a proposição do "menor como objeto do direito penal" e os que denfendiam o "menor enquanto sujeito de direitos" (Rizzini, 1995, p. 146).

\section{A ditadura militar e a Fundação Nacional do Bem-Estar do Menor (1964-1985)}

Com o golpe militar de 1964, a Escola Superior de Guerra, por meio da Doutrina de Segurança Nacional, estabeleceu a Política Nacional de BemEstar do Menor - PNBEM -, que introduziria a rede nacional da Fundação do Bem-Estar do Menor - Funabem -, em 1970, incorporando o patrimônio material e as atividades cotidianas do SAM. Na presidência do general Castello Branco, o SAM foi extinto. O Golpe Militar de 1964, entretanto desarticulou o movimento que propunha um atendimento menos repressivo, uma estratégia integrativa e voltada para a família, uma vez que, o novo ordenamento institucional reverteu todos os propósitos educativos e integrativos propostos por lei ao novo órgão (Faleiros, 1995).

Em 1968, o Fundo das Nações Unidas para Infância firmou acordo com o governo brasileiro. Paradoxalmente, e em plena atividade da ditadura, o país assumiria formalmente os preceitos da Declaração Universal dos Direitos da Criança, embora na prática o que se constataria era a aprovação de um novo código de menores, mais repressivo. Paralelamente, nos anos 70 do século passado, os debates sobre os "direitos dos menores" retornariam ao centro das discussões, partindo, mais uma vez, de divergências entre juristas e legisladores, 
influenciados pelas Convenções Internacionais pelos Direitos da Infância e pelos fóruns internacionais, como a Associação Internacional de Juízes de Menores. Essas convenções propunham que a magistratura favorecesse a promoção da família e da comunidade no cuidado da criança e do adolescente, a salvaguarda dos seus direitos, considerando-os sujeitos de direitos, o que reiterava os princípios enunciados pela Declaração dos Direitos da Criança, de 1959 (Rizzini, 1995, p. 155).

Entretanto, a proposta de uma Declaração dos Direitos da Criança não encontrou repercussão política na férrea doutrina militar. Aprovou-se o Código de Menores de 1979, lei que se alinhava aos moldes do antigo Código de Menores da primeira República, consubstanciando a doutrina de situação irregular do menor, segundo a qual "os menores são sujeitos de direito quando se encontrarem em estado de patologia social, definida legalmente [...], fazendo-se da vítima um réu e tornando a questão ainda mais jurídica e assistencial" (Faleiros, 1995, p. 8I).

Paralelamente, o arcabouço institucional e organizacional das políticas sociais se consolidava mediante profunda transformação na estrutura institucional e financeira das políticas sociais, devida à aceleração dos processos de industrialização, urbanização e da transformação da estrutura social brasileira.

Com a ausência total de canais de participação política, a autonomia da burocracia estatal se fortaleceu pela atuação da tecnocracia e dos militares dentro do aparato estatal, com o controle centralizado da gestão de programas e a implantação de mecanismos de financiamento articulados ao interesse empresarial-capitalista. Tais fatores possibilitaram a articulação de interesses particularistas no interior da máquina estatal e o aprofundamento do esquema populismo-clientelismo-pratonagem. $\bigcirc$ caráter técnico-administrativo que caracterizou a formulação das políticas governamentais expressava a despolitização da tomada de decisões com a exclusão de qualquer possibilidade de representação social como fundamento das relações Estado/sociedade, assim como, qualquer tipo de fiscalização e controle do poder estatal-executivo por parte da sociedade.

As mudanças se fizeram notar no período de 1974 a 1980 pelo progressivo desmantelamento da ordem autoritária, caracterizado pela ampliação do espaço político-organizacional relacionado às decisões governamentais no campo social, pelo redirecionamento das políticas sociais, com prioridade ao atendimento de segmentos de baixa renda e pela expansão das estruturas estatais. 
Na década de 80 do século passado, o sistema social refletiria a crise econômica mundial paralelamente à crescente organização de diversos setores da sociedade em favor da liberdade e da democracia. Esses fatores culminaram no desmonte do regime militar. Os anos subsequentes foram acompanhados por uma série de denúncias sobre as injustiças cometidas no atendimento infantojuvenil no país, desvelando "a distância existente entre crianças e menores no Brasil, mostrando que crianças pobres não tinham sequer direito à infância. Estariam elas em situação irregular" (Rizzini, 1995, p. 160).

Esse recorte histórico demonstrou o longo processo de instituição da infância como objeto de dispositivos jurídicos, legislativos e assistenciais, do início da república até o final do século $X X$, quando a criança passou à condição de sujeito de direitos, tendo sido redimensionadas assim as concepções no âmbito teórico, jurídico e técnico do atendimento à infância no país.

\section{INFÂNCIA E ADOLESCÊNCIA: SUJEITOS DE DIREITOS E OBJETO DE PROTEÇÃO DO ESTADO (1985-2006)}

Nesta parte, procura-se situar as transformações legais voltadas à infância e adolescência durante a redemocratização política da sociedade brasileira, percurso que representou a consolidação da sociedade civil em torno da luta por direitos políticos, civis e sociais, e a noção de direitos das crianças e dos adolescentes, que marcaram a década de 1990.

A partir de 1980, a crescente organização da sociedade contra a ditadura e em favor da liberdade e da democracia, levou à redemocratização da sociedade e do Estado brasileiro: reconquistaram-se os direitos de expressão individual e coletiva, de organização popular e partidária, de greve, de voto, culminando nas mobilizações sociais de 1984// 985 que reivindicavam as eleições diretas para presidente da república.

A partir da regulamentação da Constituição Federal de 1988 foram instituídas as seguintes ordenações legais com base nos direitos sociais: o Estatuto da Criança e do Adolescente (Lei Federal n. 8.069/90), a Lei Orgânica da Saúde - LOS (Lei Federal n. 8.080/90); a criação do Conselho Nacional dos Direitos da Criança e do Adolescente - Conanda (Lei Federal n. 8.242/91); a Lei Orgânica da Assistência Social - Loas (Lei Federal n. 8.742/93), a Lei de Diretrizes e Bases da Educação Nacional - LDBEN (Lei Federal n. 9.394/96); a Lei Orgânica de Segurança Alimentar - Losan (Lei Federal n. I I.346/06), 
além da recente integração dos serviços sociais, por meio do Sistema Único de Assistência Social - Suas. Esse aparato legal criou condições de assegurar as diretrizes de políticas sociais básicas com capacidade de atender às necessidades primordiais da população (Quadro 2), como saúde, educação, cultura, alimentação, esporte, lazer e profissionalização, considerado o acesso aos direitos sociais uma dimensão da cidadania (Brasil, 1988).

QUADRO 2

CONTEXTUALIZAÇÃO HISTÓRICA DO ATENDIMENTO À INFÂNCIA E À ADOLESCÊNCIA NO BRASIL (1985-2006)

\begin{tabular}{|c|c|c|}
\hline Períodos & Principais normatizações e legislações & Principais características \\
\hline $\begin{array}{l}\text { Redemocratização e } \\
\text { Estatuto da Criança } \\
\text { e do Adolescente } \\
(1985-2006)\end{array}$ & 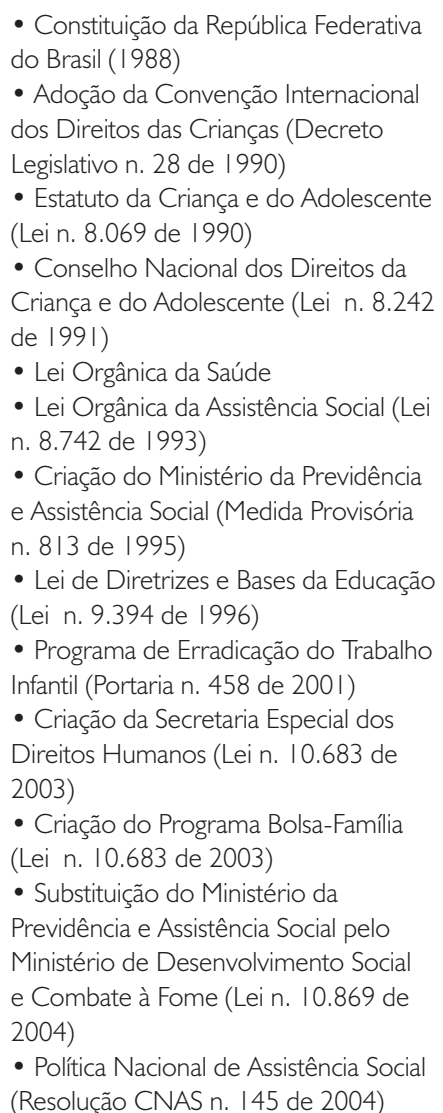 & $\begin{array}{l}\text { - Novo padrão político, } \\
\text { jurídico e social } \\
\text { - Institucionalização da } \\
\text { infância e da adolescência } \\
\text { como sujeito de direitos } \\
\text { - Descentralização, } \\
\text { municipalização, controle e } \\
\text { participação social }\end{array}$ \\
\hline
\end{tabular}

(continua) 


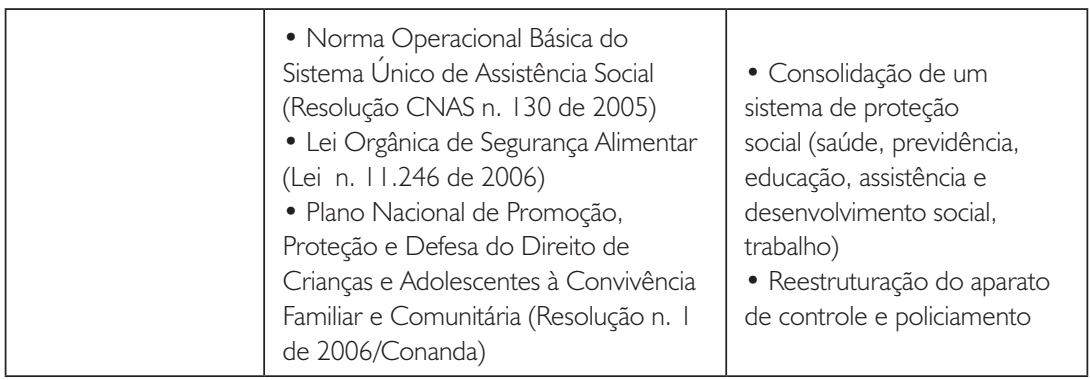

Paralelamente ao processo de elaboração e implementação das políticas sociais destinadas ao atendimento à criança e ao adolescente, o período de redemocratização se caracterizou pela reforma administrativa do Estado, que envolveu a descentralização e a municipalização de políticas públicas e, também, a institucionalização do controle social, com a criação de conselhos e espaços públicos de interlocução e cogestão política, bem como a mobilização e participação social de diversos setores da sociedade civil.

No plano político-econômico, as mudanças promovidas a partir dos anos 80 do século passado se caracterizaram pelo embate com o neoliberalismo e as transformações do sistema de políticas sociais. $\bigcirc$ dilema que se estabeleceu para a década de 1990 e para o início do século XXI foi o de conciliar crescimento econômico e combinar a responsabilidade social do Estado/sociedade na formulação, articulação e gestão de políticas públicas, com um cenário de escassez de recursos públicos, de um lado, e demandas por uma democracia social, de outro.

Nesse contexto, a estratégia de constituição de um sistema de proteção social no país se baseou nos modelos tradicionais de programas destinados à transferência monetária contemplando famílias em situação de vulnerabilidade social por intermédio de políticas sociais compensatórias e complementares, objetivando aumentar o acesso à alimentação, saúde e educação básica, considerados fatores de grande potencial para a redução das desigualdades.

A organização da sociedade civil exerceu a função política destinada ao espaço público no processo de democratização do Estado brasileiro, tanto no que diz respeito à capacidade de tornar as decisões do Estado permeáveis à influência dos setores da sociedade civil, quanto na constituição de um espaço legítimo de lutas contra a exclusão política e social, por meio da valorização e do reconhecimento do "outro" como sujeito portador de direitos. Contribuiu, 
por fim, para consolidar a aprendizagem de uma cultura de direitos e cidadania (Grupo de Estudos sobre a Construção Democrática - Gecd - 1999).

Nesse contexto de mudanças os movimentos sociais conseguiram mobilizar, na Assembléia Constituinte, a criação da Comissão Nacional Criança Constituinte, em 1987, e consequentemente, a formação da Frente Parlamentar Suprapartidária pelos Direitos da Criança. A Constituição de 1988 redefiniu, nos artigos 227, 228 e 229, a posição e a representação da criança na sociedade, reconhecendo-a como sujeito de direitos e objeto de proteção integral.

Estatuto da Criança e do Adolescente, promulgado em 13 de julho de 1990, substituiu a repressiva doutrina do Código de Menores de 1979, e instaurou novas referências políticas, jurídicas e sociais. Ao definir em seus primeiros artigos que "toda criança e todo adolescente têm direito à proteção integral, considerando-os como sujeito de direitos individuais e coletivos, cuja responsabilidade é da família, da sociedade e do Estado" (Brasil, 1990), o país baniu a categoria "menor" do arcabouço conceitual e jurídico, introduzindo a moderna noção de adolescência e incorporando os preceitos da Convenção Internacional dos Direitos da Criança, de 1989.

O ECA expressa, portanto, os direitos das crianças e dos adolescentes e norteia toda política de atendimento distribuída em quatro linhas de ações:

a. as políticas sociais básicas de caráter universal, como saúde, educação, alimentação, moradia, etc. (art. 87, item I);

b. as políticas e programas de assistência social (art. 87, item II), de caráter supletivo, para aqueles de que delas necessitem;

c. as políticas de proteção, que representam serviços especiais de atendimento médico e psicossocial às vítimas de negligência, maus-tratos, exploração, abuso e opressão (art. 87, item III); os serviços de identificação e localização de pais, responsáveis, crianças e adolescentes desaparecidos (art. 87, IV);

d. as políticas de garantias de direitos, que representam as entidades e os aparatos jurídicos e sociais de proteção dos direitos individuais e coletivos da infância e juventude (art. 87, item V).

No artigo 88 (item I a VI), a legislação propõe as diretrizes que compõem essa política: a municipalização; criação e manutenção de programas específicos, considerando a descentralização político-administrativa; criação de conselhos 
municipais, estaduais e nacionais dos direitos da criança e do adolescente, como órgãos deliberativos e controladores das ações em todos os níveis, asseguradas a participação popular paritária por meio de organizações representativas, segundo leis federais, estaduais e municipais; manutenção de fundos nacional, estadual e municipal vinculados aos respectivos conselhos; mobilização da opinião pública no sentido da indispensável participação dos diversos segmentos da sociedade e, integração operacional de órgãos do Judiciário, Ministério Público, Defensoria, Segurança Pública e Assistência Social.

O Sistema de Garantia de Direitos, que representa o arcabouço da política de atendimento à infância e adolescência no Brasil, tem sido considerado um conjunto de instituições, organizações, entidades, programas e serviços de atendimento infanto-juvenil e familiar, os quais devem atuar de forma articulada e integrada, nos moldes previstos pelo ECA e pela Constituição Federal, com o intuito de efetivamente implementar a Doutrina da Proteção Integral por meio da política nacional de atendimento infanto-juvenil.

A partir desse marco, destacam-se a institucionalização do Conselho Nacional de Direitos da Criança e do Adolescente - Condeca -, em |991, dando continuidade à regulamentação das disposições da Constituição e do Estatuto; a Lei Orgânica de Assistência Social - Loas -, em 1993, que priorizou o atendimento à criança e à adolescência previsto nas ações de atendimento às políticas municipais da criança e do adolescente, por meio da assistência social. Em 1995, a Medida Provisória n. 8| 3 transformou o então Ministério da Previdência Social em Ministério da Previdência e Assistência Social - MPAS -, criando a Secretaria Nacional de Assistência Social - SAS -, como órgão da gestão federal. Em 1996, também foi criado o Programa de Erradicação do Trabalho Infantil - Peti -, por intermédio da SAS. Sua emergência e implementação foi consagrada como desdobramento das articulações do Fórum Nacional de Erradicação do Trabalho Infantil, instituído por meio da Portaria n. 458 de 200 I. A inexistência de um órgão específico para o controle e articulação da política social culminou na criação do Ministério do Desenvolvimento Social e Combate à Fome - MDS -, pela Medida Provisória n. 163, de janeiro de 2004, e transformada na Lei n. 10.869, de maio de 2004. O MDS ${ }^{2}$ passou a coordenar a política de desenvolvimento social, segurança ali-

2. O Ministério de Desenvolvimento Social e Combate à Fome substituiu o Ministério Extraordinário de Segurança Alimentar e Combate à Fome, instituído em 2003, e responsável pelo Programa Nacional de Acesso à Alimentação (Programa Fome Zero). 
mentar e nutricional, assistência social e renda de cidadania. Dando continuidade ao processo de operacionalização da seguridade social, a elaboração da Política Nacional de Assistência Social - PNAS - , em 28 de outubro de 2004, definiu as diretrizes para o Sistema Único de Assistência Social - Suas -, conforme a Loas, tratando das condições para a extensão e universalização da proteção social básica e especial à população em geral e, em especial, à criança e ao adolescente em situação de vulnerabilidade social. $\bigcirc$ Suas foi implementado a partir da publicação da Norma Operacional Básica - NOB -, do Sistema Único de Assistência Social (Resolução do Conselho Nacional n. 130, de julho de 2005), que regulamentou o dispositivo da PNAS e definiu os parâmetros para a regulamentação e implementação do Suas em todo o território nacional (Brasil, 2004, p. 33).

Nesse contexto, processa-se a reorganização dos serviços sociais visando à integração de objetivos e formas de ação em relação a um público-alvo, juntamente, com a noção de complementaridade entre intervenção estatal e privada no atendimento às políticas de direitos infanto-juvenis, como ocorreu nos últimos anos com a saúde, a educação e, recentemente com a assistência social. A implementação do Programa Bolsa-Família (Lei n. 10.683 de 2003), por meio do MDS, retrata a unificação operacional de gestão das ações de transferência de renda. Por exemplo, tal programa integrou diversas ações existentes, como a Bolsa-Escola (programa nacional de renda mínima, vinculado ao Ministério da Educação); a Bolsa-Alimentação (programa nacional de renda mínima para combate à mortalidade infantil e desnutrição, vinculado ao Ministério da Saúde); o Cartão-Alimentação (programa nacional de acesso à alimentação, criado no âmbito do Programa Fome Zero e vinculado ao extinto Ministério Extraordinário da Segurança Alimentar); o programa Auxílio-Gás, vinculado ao Ministério das Minas e Energia, e o Peti, este último a partir de 2006.

No âmbito do Ministério da Justiça, constituiu-se o Departamento da Criança e do Adolescente - DCA -, órgão localizado junto a Secretaria de Direitos de Cidadania, por intermédio do Decreto n. I.796 de 1996, estabelecendo linhas gerais da Política de Promoção e Defesa dos Direitos da Criança e do Adolescente. Posteriormente, em 1998, a Secretaria de Direitos de Cidadania foi extinta, passando o DCA à estrutura da Secretaria Nacional de Direitos Humanos que, em janeiro de 1999, passou à categoria de Secretaria de Estado de Direitos Humanos. Em 2003, o Departamento da Criança e do Adolescente foi substituído pela Secretaria Especial dos Direitos Humanos - 
SDHE -, de acordo com a Lei n. 10.683. A SEDH ficou responsável pela "articulação e implementação de políticas públicas de promoção e proteção de direitos", e foi composta por diversos conselhos nacionais (direitos humanos, criança e adolescente, idoso, combate à discriminação e portadores de deficiência), e pela Subsecretaria de Promoção dos Direitos da Criança e do Adolescente - SPDCA -, cujas ações visam o fortalecimento do Sistema de Garantias de Direitos, bem como a elaboração das diretrizes políticas e do Plano Nacional de Promoção, Defesa e Garantia do Direito de Crianças e Adolescentes à Convivência Familiar e Comunitária (Brasil, 2006a) e a discussão sobre Sistema Nacional de Atendimento Socioeducativo - Sinase (Brasil, 2006).

O Sistema de Garantia de Direitos está composto por três eixos: promoção, defesa e controle social. No eixo da Promoção, destacam-se as políticas sociais básicas (saúde, saneamento, educação, moradia etc.), as ações do poder executivo e do conselho de direitos. Já o eixo da Defesa consubstancia-se pelas políticas de assistência social e proteção especial, pelos Conselhos Tutelares, pelos centros de defesa da criança e do adolescente, pelo Ministério Público, pelo Judiciário e pela Segurança Pública, com suas delegacias especializadas. Por fim, o eixo do Controle Social, composto pelos Conselhos de Direitos, Fóruns de Defesa dos Direitos das Crianças e dos Adolescentes e outros instrumentos judiciais e institucionais de controle interno da administração pública como a Controladoria, Tribunal de Contas, Ministério Público, Poder Judiciário etc. (Brasil, 2006).

No âmbito do sistema de proteção social, o processo de reestruturação institucional das políticas sociais impulsionadas em direção à economia competitiva globalizada pressupôs um dinâmico planejamento, como diretriz central para as políticas e os investimentos sociais, bem como um sistema tecnológico de avaliação dessa ação social e institucional. Colaboração, complementaridade, parceria e redes sociais se transformaram em vocábulos recorrentes entre os gestores, implementadores e executores das políticas sociais, tanto de setores estatais como "não-estatais".

Após a reforma administrativa, aprofundou-se e se multiplicou o espaço contratual de "prestação de serviços", na área social, bem como, se institucionalizaram os mecanismos de participação social nas decisões de políticas públicas, o que, de certa maneira, deslocou os movimentos sociais de suas formas tradicionais de atuação, canalizando-os para ações menos contestatórias, 
como a das organizações não governamentais - ONGs -, das organizações sociais, além das ações filantrópicas e assistenciais tradicionais (Dagnino, Oliveira, Panfichi, 2006).

Essas mudanças no padrão de atendimento dos serviços sociais coexistem à sombra de antigas práticas benevolentes que antecederam o debate sobre os direitos civis, políticos e sociais e, normalmente, se pautavam em ações de caráter assistencialista e/ou clientelista não sendo concebidas como parte do exercício e do reconhecimento dos direitos civis e sociais de cidadania.

Observou-se desse modo, nas últimas décadas, a entrada em cena de "novos" atores no campo do atendimento às políticas sociais à infância e à juventude. Entre eles encontram-se os nichos empresariais criados pela nova economia de mercado "responsável" do ponto de vista ambiental e social, e as novas organizações sociais de caráter público (ONGs, organizações da sociedade civil de interesse público - Oscips -, fundações etc.). Muitas dessas organizações foram chamadas de "terceiro setor", e são responsáveis pela rápida expansão de fundações empresariais, entidades caritativas, filantrópicas e organizações sociais que, muitas vezes, em suas práticas endossam discursos sobre a ineficiência estatal, ou denegam a eficiência do Estado para promover e garantir pactos assentados no princípio de cidadania, defendendo uma suposta eficiência do mercado ou a existência de uma "virtuosidade" das ações da sociedade civil (Passone, 2007).

O perfil dessas organizações pode ser um indicador da natureza democrática e cidadã ou clientelista dos pactos atuais entre Estado e sociedade, à medida que reconhecem o cidadão como portador de direitos e responsabilidades, ou reforçam os antigos moldes de dependência e patrimonialismo nas relações sociais. $\bigcirc$ agravante é um cenário delimitado por intervenções oriundas tanto de contextos internacionais quanto nacional, marcadamente fragmentado entre formas e níveis de mobilização e organizações sociais.

\section{CONSIDERAÇÕES FINAIS}

O recorte histórico apresentado resgatou as principais características do aparato administrativo e legislativo relativo à constituição da infância e adolescência no país, o qual passou por pressões e reformulações ao longo do século $X X$. 
O recente fortalecimento das organizações da sociedade civil e a discussão sobre a atuação de novos atores sociais no atendimento às políticas sociais têm permitido iluminar o caráter heterogêneo da sociedade civil como espaço de disputas de interesses, principalmente em relação ao Estado e aos recursos destinados a essas políticas. Isso reforça a importância da redefinição dos limites entre o interesse público e o privado, bem como a tentativa de constituir uma esfera pública com qualidade ético-política, capaz de repor e pactuar socialmente projetos políticos com a sociedade embasados na garantia de direitos civis, políticos e sociais, e no combate aos projetos políticos autoritários e a formas privatizadas de poder.

Contudo, são grandes os riscos de que as ações oriundas da sociedade civil e da iniciativa privada desloquem a noção histórica de direitos pessoais e coletivos, instituídos na recente ordenação democrática da sociedade brasileira, para antigas relações sociais mediadas pela noção de benevolência, caridade, compaixão etc., reforçando a cultura pautada por relações afetivas de dependência - matriz de políticas impregnadas pelo paternalismo, clientelismo e populismo. Para esses casos, a avaliação, a transparência das ações e a prestação de contas à comunidade, o planejamento democrático e participativo e as ações integradas são bons exemplos do caminho que o Estado e a sociedade deveriam perseguir, para alcançarem juntos níveis mais autônomos de desenvolvimento individual e coletivo.

O conflito oriundo da nova cultura de direitos e das antigas práticas assistencialistas de benevolência e compaixão é uma das constatações a que se chega. Ele também se constitui em grande risco para a efetiva implementação das políticas sociais de atendimento à infância e à adolecência.

\section{REFERÊNCIAS BIBLIOGRÁFICAS}

ARIÉS, P. História social da criança e da família. 2. ed. Rio de Janeiro: Zahar, 1981.

BRASIL. Conselho Nacional dos Direitos das Crianças e Adolescentes. Sistema nacional de atendimento socioeducativo. Brasilia, 2006. Disponível em: <http://www.mj.gov/sedh /ct/ spdca/sinase/SINASE.pdf>. Acesso em: 25 nov. 2008.

. Constituição da República Federativa do Brasil. Brasília: Senado, 1988.

. Leis e decretos. Lei n.8069, de 13 de julho de 1990: dispõe sobre o Estatuto da

Criança e do Adolescente e dá outras providências. Brasília, 1990. 
. Ministério do Desenvolvimento Social. Política nacional de assistência social. Brasília, 2004.

. Ministério da Justiça. Estatuto da criança e do adolescente. Brasília: CBIA, Unicef, 1990a.

. Secretaria Especial dos Direitos Humanos. Ministério de Combate à Fome. Plano nacional de promoção, proteção e defesa do direito de crianças e adolescentes à convivência familiar e comunitária. Brasília, 2006a. Disponível em: <http://www.cecif.org.br/word/ pmcfcl I_12.pdf> Acesso em: dez. 2006.

CARVALHO, J. M. Cidadania no Brasil: o longo caminho. 2. ed. Rio de Janeiro: Civilização Brasileira, 2004.

DAGNINO, E.; OLVERA, A. J.; PANFICHI, A. (Org.). A Disputa pela construção democrática na América Latina. São Paulo: Paz e Terra, 2006.

DRAIBE, S. Repensando a política social: dos anos 80 ao início dos 90. In: PAULANI, L. M.; SOLA, L. (Org.). Lições da década de 80. São Paulo: Edusp, 1995. p. 201 -224.

FALEIROS, V. P. Infância e processo político no Brasil. In: PILOTTI, F.; RIZZINI, I. (Org.). A Arte de governar crianças: a história das políticas sociais, da legislação e da assistência à infância no Brasil. Rio de Janeiro: Instituto Interamericano del Niño, 1995. p. 49-98.

GRUPO DE ESTUDOS SOBRE A CONSTRUÇÃO DEMOCRÁTICA. Esfera pública e democracia no Brasil. In: Idéias: Revista do Instituto de Filosofia e Ciências Humanas, Campinas, n.5/6, p. 43-75, 1999. (Os Movimentos sociais e a construção democrática: sociedade civil, esfera pública e gestão participativa).

MARSHALL, T. S. Cidadania, classe social e status. Rio de Janeiro: Zahar, 1967.

NASCIMENTO, M. E. P. Do adulto em miniatura à criança como sujeitos de direitos: a construção de políticas de educação para a criança de tenra idade na França, 200 I. Tese (Doutorado em Educação) - Universidade Estadual de Campinas, Campinas.

PASSONE, E. F. Políticas sociais de atendimento à infância e juventude: o caso da Fundação Abrinq. 2007. Dissertação (Mestrado em Educação) - Universidade Estadual de Campinas, Campinas.

PILOTTI, F. Crise e perspectivas da assistência à infância na América Latina. In: PILOTTI, F; RIZZINI, I. (Org.). A Arte de governar crianças: a história das políticas sociais, da legislação e da assistência à infância no Brasil. Rio de Janeiro: Instituto Interamericano Del Niño, 1995. p. $12-45$. 
RIZZINI, I. A Criança e a lei no Brasil: revisitando a história (I 822-2000). Rio de Janeiro: Unicef, Cespi/USU, 2000.

. Crianças e menores do pátrio poder ao pátrio dever: um histórico da legislação para a infância no Brasil ( 830 - 1990) In: PILOTTI, F; RIZZINI, I. (Org.). A Arte de governar crianças: a história das políticas sociais, da legislação e da assistência à infância no Brasil. Rio de Janeiro: Instituto Interamericano Del Niño, 1995. p.99- 168.

. O Século perdido: raízes históricas das políticas públicas para a infância no Brasil. Rio de Janeiro: Universitária, 1997.

RIZZINI, I.; NAIFF, L. A. M.; BAPTISTA R. (Coord.). Acolhendo crianças e adolescentes: experiências de promoção do direito à convivência familiar e comunitária no Brasil. São Paulo: Cortez; Brasília: Unicef; Rio de Janeiro: PUC-Rio, 2006.

ROMANELLI, O. História da educação no Brasil. Petrópolis: Vozes, I99I.

SANTOS, W. G. A Trágica condição da política social. In: ABRANCHES, S. et al. (Org.). Política social e combate à pobreza. Rio de Janeiro: Jorge Zahar, 1989. p.33-63.

. Cidadania e justiça: a política social na ordem brasileira. Rio de Janeiro: Campos,

1979.

UNICAMP. Núcleo de Estudos de Políticas Públicas. O Sistema de proteção social no Brasil. Campinas, 1991.

Recebido em: maio 2009

Aprovado para publicação em: dezembro 2009 